https://helda.helsinki.fi

\title{
How near is near infrared spectroscopy in pre-hospital care?
}

\section{Skrifvars, Markus B.}

2020-01

Skrifvars , M B \& Aneman , A 2020 , ' How near is near infrared spectroscopy in pre-hospital care? ' , Acta Anaesthesiologica Scandinavica , vol. 64 , no. 1 , pp. 2-3 . https://doi.org/10.1111/aas.13467

http://hdl.handle.net/10138/325534

https://doi.org/10.1111/aas.13467

acceptedVersion

Downloaded from Helda, University of Helsinki institutional repository.

This is an electronic reprint of the original article.

This reprint may differ from the original in pagination and typographic detail.

Please cite the original version. 
PROFESSOR MARKUS SKRIFVARS (Orcid ID : 0000-0002-0341-0262)

Article type : Editorial

How near is near infrared spectroscopy in pre-hospital care?

Authors:

Markus B Skrifvars ${ }^{1,2}$, Anders Aneman ${ }^{3,4,5}$

Authors Affiliations:

1. Department of Emergency Care and Services, University of Helsinki and Helsinki University Hospital

2. Department of Anesthesiology, Intensive Care and Paine Medicine, University of Helsinki and Helsinki University Hospital

3. Intensive Care Unit, Liverpool Hospital, Sydney, Australia

4. University of New South Wales, South Western Sydney Clinical School, Sydney, Australia

5. Macquarie University, Faculty of Medicine and Health Sciences, Sydney, Australia

Corresponding Author:

Markus B Skrifvars

1.Department of Emergency Care and Services, University of Helsinki and Helsinki University Hospital

2.Department of Anesthesiology, Intensive Care and Paine Medicine, University of Helsinki and Helsinki University Hospital

Email: markus.skrifvars@hus.fi

This article has been accepted for publication and undergone full peer review but has not been through the copyediting, typesetting, pagination and proofreading process, which may lead to differences between this version and the Version of Record. Please cite this article as doi: 10.1111/aas.13467

This article is protected by copyright. All rights reserved. 
Maintaining an adequate cerebral oxygenation appears intuitively as a crucial goal for the acute care of the critically injured patient ${ }^{1}$. The concept of avoiding secondary brain injury represents a corner stone of modern neurointensive care and these principles should ideally be applied also during the pre-hospital phase and patient transport. Delivery of oxygen to the brain is governed by the cerebral perfusion pressure largely determined by mean arterial blood pressure (in the absence of significant intracranial hypertension) and the arterial blood oxygen content, partly reflected by peripheral pulse oximetry ${ }^{1}$. Thus, the arterial blood pressure and oxygen saturation have formed the standard clinical endpoints to support cerebral oxygenation given the paucity of methods to monitor brain perfusion, that when available are too complex for use in the austere prehospital environment ${ }^{2}$.

Near-infrared spectroscopy (NIRS) has been studied as a method to monitor cerebral tissue oxygenation and to possibly detect cerebral ischaemia, but has thus far not been commonly established in hospital clinical routine ${ }^{3}$. Very limited data exist regarding the application of NIRS in the prehospital setting ${ }^{4}$. The collection of reliable and preferably continuous data is challenging for most monitoring devices in the prehospital environment and certainly so for elaborate techniques such as NIRS. In this issue of Acta Anaesthesiologica Scandinavica, Weatherall and colleagues report preliminary feasibility data from a prospective observational on the use of continuous NIRS monitoring during retrieval of trauma patients ${ }^{5}$. The NIRS sensors were applied by a dedicated researcher who was not part of the clinical team to the forehead bifrontally and to one forearm, unless precluded by haematomas or lacerations. These anatomical sites for NIRS have been studied fairly extensively in the in-hospital setting. The authors report that the quality of the NIRS monitoring was acceptable for more than $70 \%$ of the prehospital time in $45 / 63$ patients for all sensor sites and in 57/63 patients for at least two sensor sites. Introducing NIRS monitoring did not prolong the on scene or transport times, with the caveat that additional study personnel was utilized. The authors are to be commended on undertaking this study within the logistical constraints of prehospital emergency care and for their transparent presentation of results, including important limitations.

The authors used a threshold value of $70 \%$ for an adequate NIRS signal to assess feasibility. This cut-off appears appropriate and would certainly allow for the determination of cerebral oximetry trends, both as driven by the trauma induced pathology and responses to therapeutic interventions. A sensitivity analysis of using a higher threshold was not performed. Inferences made in the text to monitoring of cerebral autoregulation warrant circumspection as both arterial pressure and NIRS signals would need to be captured with appropriate, contemporaneous quality. Playing the devil's advocate, one could argue that the signal acquisition per se does not equate to meaningful information, as provocatively demonstrated by Kahn er al ${ }^{6}$. Conversely, changes in the NIRS signal were recently reported to reflect physiological changes determining the NIRS reading ${ }^{7}$. Does the feasibility to capture a NIRS signal pre-hospitally lead to the monitoring fallacy that we make important what we can measure rather than measuring what is important? The study was not designed to capture any associations with patient centered outcomes and this limitation is clearly acknowledged by the authors. The rapid physiological changes seen in the unstable trauma patient, in whom NIRS could provide very useful information, might also challenge

This article is protected by copyright. All rights reserved. 
the inherent and proprietary algorithms used to derive the tissue oxygenation signal, including the volume partition between arterial and venous vascular compartments. It is important to remember that different NIRS devices perform differently, in particular the ability to measure tissue oxygenation in the extreme low range. Thus, the results of this study need to be confirmed using other devices. Establishing the feasibility of NIRS monitoring is obviously a sine qua non for any further studies investigating clinical associations or interventions targeting management of blood pressure or haemoglobin, oxygen and carbon dioxide levels that all may influence NIRS ${ }^{8,9}$. The study by Weatherall et al provide information useful to inform the design and sample size of future trials.

Prehospital NIRS monitoring has been applied almost exclusively in out of hospital cardiac arrest patients during ongoing resuscitation ${ }^{10}$, whilst the results of these studies support the feasibility of NIRS monitoring and its value in detecting return of spontaneous circulation ${ }^{10}$. Patients with major trauma with and without traumatic brain injury patients may of course differ, especially concerning the possible presence of treatable intracranial lesions that may increase intracranial pressure and hamper cerebral perfusion. Traditionally these patients are identified by a dilated pupil, but in many cases this is already too late ${ }^{1}$. A recent study by Angerman et al investigated the use of NIRS monitoring during induction of anaesthesia performed by the helicopter emergency medical service in the pre-hospital setting prior to transport. Again, NIRS monitoring was feasible with bifrontal signals obtained in 29/31 cases for $95 \%$ of a total monitoring time of 1335 minutes. Substantial changes in cerebral oxygenation were observed also in the absence of changes in vital signs and the authors concluded that NIRS monitoring provided useful information beyond standard monitoring. It should be noted that the extreme haemodynamic changes associated with cardiac arrest might be more significant than those occurring during transport of trauma patients, e.g. a similar magnitude of change in cerebral tissue oxygenation from the extreme low of $25-35 \%$ could be different compared to an increase from the normal low of $50 \%$.

The even bigger question is of course what the clinician should do with the NIRS value; will it influence patient management? Intuitively one would think that aiming high must be good. However, in post cardiac arrest patients, in the largest study conducted to date, no association was found between mean NIRS values obtained during eth first 36 hours in the ICU with either neuron specific enolase, as a biomarker of neurological injury, or outcome ${ }^{11}$. One other possibility would be to use NIRS to identify the optimal cerebral perfusion setting for each individual patient, but this is likely not possible in the pre-hospital setting. More probable would be the identification of the critical patient with seemingly stable vital functions but nonetheless signs of cerebral ischaemia as shown in the by Ångerman and colleagues $^{12}$. The interventions available may include modifying blood oxygen and carbon dioxide levels, improving mean arterial pressure ${ }^{8,9,13,14}$ or administration of agents aimed at rapidly lowering the intracranial pressure ${ }^{1}$.

There is plenty of work ahead before NIRS is in routine use in any clinical setting, even more so in the challenging pre-hospital setting. Weatherall and colleagues are providing valuable data paving the way on the immensely difficult path of providing more detailed continuous monitoring in these very complex patients.

This article is protected by copyright. All rights reserved. 


\section{REFERENCES:}

1. Stocchetti N, Carbonara M, Citerio G, Ercole A, Skrifvars MB, Smielewski P, Zoerle T, Menon DK. Severe traumatic brain injury: targeted management in the intensive care unit. Lancet Neurol 2017; 16: 452-64.

2. Badjatia N, Carney N, Crocco TJ, Fallat ME, Hennes HM, Jagoda AS, Jernigan S, Letarte PB, Lerner EB, Moriarty TM, Pons PT, Sasser S, Scalea T, Schleien CL, Wright DW, Brain Trauma F, Management BTFCfG. Guidelines for prehospital management of traumatic brain injury 2nd edition. Prehosp Emerg Care 2008; 12 Suppl 1: S1-52.

3. Ghosh A, Elwell C, Smith M. Review article: cerebral near-infrared spectroscopy in adults: a work in progress. Anesth Analg 2012; 115: 1373-83.

4. Kahraman S, Kayali H, Atabey C, Acar F, Gocmen S. The accuracy of nearinfrared spectroscopy in detection of subdural and epidural hematomas. J Trauma 2006; 61: 1480-3.

5. Weatherall A, Poynter E, Garner A, Lee A. Near-infrared spectroscopy monitoring in a pre-hospital trauma patient cohort: An analysis of successful signal collection. Acta Anaesthesiol Scand 2019.

6. Kahn RA, Anyanwu A. Near-infrared spectroscopy in vegetables and humans: An observational study. Eur J Anaesthesiol 2018; 35: 907-10.

7. Wood MD, Jacobson JA, Maslove DM, Muscedere JG, Boyd JG, Cerebral O, Neurological Outcomes Following Critical Illness Research G. The physiological determinants of near-infrared spectroscopy-derived regional cerebral oxygenation in critically ill adults. Intensive Care Med Exp 2019; 7: 23.

8. Jakkula P, Pettila V, Skrifvars MB, Hastbacka J, Loisa P, Tiainen M, Wilkman E, Toppila J, Koskue T, Bendel S, Birkelund T, Laru-Sompa R, Valkonen M, Reinikainen M, group Cs. Targeting low-normal or high-normal mean arterial pressure after cardiac arrest and resuscitation: a randomised pilot trial. Intensive Care Med 2018; 44: 2091-101.

9. Jakkula $P$, Reinikainen $M$, Hastbacka J, Loisa $P$, Tiainen $M$, Pettila V, Toppila J, Lahde M, Backlund M, Okkonen M, Bendel S, Birkelund T, Pulkkinen A, Heinonen J, Tikka T, Skrifvars MB, group Cs. Targeting two different levels of both arterial carbon dioxide and arterial oxygen after cardiac arrest and resuscitation: a randomised pilot trial. Intensive Care Med 2018; 44: 2112-21.

10. Genbrugge C, De Deyne C, Eertmans W, Anseeuw K, Voet D, Mertens I, Sabbe M, Stroobants J, Bruckers L, Mesotten D, Jans F, Boer W, Dens J. Cerebral saturation in cardiac arrest patients measured with near-infrared technology during pre-hospital advanced life support. Results from Copernicus I cohort study. Resuscitation 2018; 129: 10713.

11. Jakkula P, Hastbacka J, Reinikainen M, Pettila V, Loisa P, Tiainen M, Wilkman E, Bendel S, Birkelund T, Pulkkinen A, Backlund M, Heino S, Karlsson S, Kopponen H, Skrifvars MB. Near-infrared spectroscopy after out-of-hospital cardiac arrest. Crit Care 2019; 23: 171. 12. Angerman S, Lankimaki S, Neuvonen N, Kirves H, Nurmi J. Prospective pilot study of cerebral near infrared spectroscopy monitoring during pre-hospital anaesthesia. Acta Anaesthesiol Scand 2018.

13. Ameloot K, De Deyne C, Eertmans W, Ferdinande B, Dupont M, Palmers PJ, Petit T, Nuyens P, Maeremans J, Vundelinckx J, Vanhaverbeke M, Belmans A, Peeters R, Demaerel $P$, Lemmens R, Dens J, Janssens S. Early goal-directed haemodynamic optimization of cerebral oxygenation in comatose survivors after cardiac arrest: the Neuroprotect postcardiac arrest trial. Eur Heart J 2019; 40: 1804-14.

This article is protected by copyright. All rights reserved. 
14.

Lang M, Raj R, Skrifvars MB, Koivisto T, Lehto $H$, Kivisaari R, von Und Zu Fraunberg M, Reinikainen M, Bendel S. Early Moderate Hyperoxemia Does Not Predict Outcome After Aneurysmal Subarachnoid Hemorrhage. Neurosurgery 2016; 78: 540-5.

This article is protected by copyright. All rights reserved. 